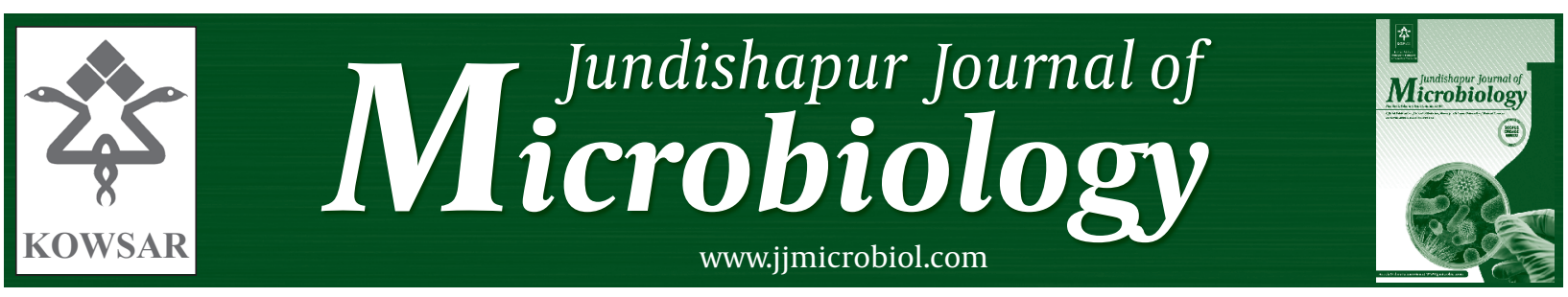

\title{
Isolation and Molecular Characterization of Toxoplasma Gondii Strains From Rats in Tehran
}

\author{
Sajad Rashidi ${ }^{1}$, Javid Sadraei ${ }^{1^{*}}$, Mehdi Fruzandeh Moghadam ${ }^{2}$, Majid Pirestani ${ }^{1}$ \\ ${ }^{1}$ Department of Parasitology, Faculty of Medical Sciences, Tarbiat Modares University, Tehran, IR Iran \\ ${ }^{2}$ Department of Medical Biotechnology, Faculty of Medical Sciences, Tarbiat Modares University, Tehran, IR Iran
}

A R T I C L E I N F O

Article type:

Original Article

Article history:

Received: 17 Oct 2011

Revised: 31 Jan 2012

Accepted: 22 Feb 2012

Keywords:

Molecular Characterization

Toxoplasma Gondii

Rats

\begin{abstract}
A B S T R A C T
Background: Toxoplasma gondii is a unicellular apicomplex organism, belonging to the Toxoplasma genus. The parasite infects humans, as well as mammalians and different species of birds, and it can be propagated in a wide range of host cells. There have been no appropriate molecular or serological studies carried out previously in Iran on the prevalence of Toxoplasma gondii in rodents.

Objectives: Therefore, the present study has been carried out to provide genetic identification and determination of wild rats in Tehran, Iran.

Materials and Methods: Forty rats in Tehran were caught with traps. Subsequently, their brains were removed under sterile conditions, DNA extraction was performed with a phenol and chloroform method. In the current study, a repetitive sequence in the genome T. gondii was used for identification with a specific primer. By sequencing the purified Polymerase Chain Reaction product, seven strains were determined out of the positive samples.

Results: Of the forty samples, 20 samples (50\%) were positive for the 529-bp band. Samples No. 21 and No. 28 had 95\% and 92\% similarity with the RH strain sequence, respectively, which had the highest identity rate. The identity rate for samples No. 16 and No. 28 was $82 \%$ and $81 \%$, respectively, which had the lowest rate of identification.

Conclusions: The contamination rate was determined to be $50 \%$ using the PCR method. It can be stated that rats play an important role in the preservation of the Toxoplasma life cycle in Tehran. According to the alignment of results obtained from the seven sequenced samples, the highest similarity was observed with the RH strain (81-95\%).
\end{abstract}

Published by Kowsar Corp, 2012. cc 3.0

- Implication for health policy/practice/research/medical education:

Based on the relatively high occurrence of this parasite in rats in Tehran, we have to consider it as a major risk factor for transmission of T. gondii in this area.

- Please cite this paper as:

Rashidi S, Sadraei J, Fruzandeh Moghadam M, Pirestani M. Isolation and Molecular Characterization of Toxoplasma Gondii Strains From Rats in Tehran. Jundishapur J Microbiol. 2012;5(4):537-41. DOI: 10.5812/jjm.2852

\section{Background}

Toxoplasma gondii is a unicellular apicomplex organism, belonging to the Toxoplasma genus. Contamination with the parasite has been reported all over the world (1-3). This unicellular parasite was first isolated by Nicole and
Manceaux in 1908, from a type of rodent called a Ctenodactylus gundi in the Pasteur Institute, Tunisia $(4,5)$. Simultaneously, Splendor, an English researcher, isolated the parasite from a laboratory rabbit (6). The parasite infects humans, as well as mammalians and different species of birds, and it can be propagated in a wide range

\footnotetext{
${ }^{*}$ Corresponding author: Javid Sadraei, Department of Parasitology, Faculty of Medical Sciences, Tarbiat Modares University, Tehran, IR Iran. Tel: +98-2182883841, Fax:+98-2182884555,E-mail:sadraeij@modares.ac.ir

DOI: $10.5812 / j \mathrm{jm} .2852$

(C) 2012 Ahvaz Jundishapur University of Medical Sciences; Published by Kowsar Corp.

This is an Open Access article distributed under the terms of the Creative Commons Attribution License (http://creativecommons.org/licenses/by/3.0), which permits unrestricted use, distribution, and reproduction in any medium, provided the original work is properly cited.
} 
of host cells (7). One of the most frequent parasitic infections of humans and other warm-blooded animals is contamination with $T$. gondii. It is estimated that $5 \times 10^{8}$ of individuals all over the world are affected by the parasite $(8,9)$. Although acquired toxoplasmosis in individuals with normal immunity usually causes only a mild disease or even remain asymptomatic, it may lead to severe symptoms and complications or even death in individuals with immune system disorders (10). In patients with AIDS, almost $30 \%$ of deaths are due to toxoplasmosis, and one of the causes of mortality in such patients is toxoplasmosis encephalitis (7-11). Congenital toxoplasmosis occurs when the mother is affected by the disease during pregnancy or if she has an immune system dysfunction. In such cases, transplacental transmission of the parasite to the fetus leads to severe complications $(11,12)$.

Using serological tests, it has been demonstrated that the prevalence of toxoplasmosis in Iran varies in different regions. Studies have shown that the rate of contamination in individuals with the parasite is; $55 \%$ for the people living along the Caspian Sea coast, $23 \%$ in the West Azerbaijan province (west of Iran), 6 and 9\% in Izeh and Sar Dasht (south of Iran), respectively, 29\% in the Fars province (central part of Iran), and 39.6\% in Kazerun town (south of Iran) (13). According to investigations carried out by the Pasteur Institute, Iran, almost $33 \%$ of the affected individuals were under 10, and females comprised $56 \%$ of the affected individuals (14). Moreover, it was reported that $75.2 \%, 47.5 \%, 41 \%$, and $72.96 \%$ of pregnant women in Amol (north of Iran), Zanjan (west of Iran), Qom province (central part of Iran), and Tabriz (west of Iran) were positive for the IgG antibody against $T$. gondii, respectively (1518). A study of stray cats in Tehran showed that $89.2 \%$ of them had anti-toxoplasmosis antibodies (19), whereas anti-T. gondii antibodies were found in 54\% of cats in Ahvaz (20). A serological evaluation of rats in Tehran, which was carried out concurrently with the current study, showed that $36.7 \%$ of the rats in Tehran were contaminated with Toxoplasma (21).

A number of rats were collected from Memphis, Tennessee, and a suspension was prepared from their brains. The suspension was injected into the rats' peritoneum. The contamination rate in these areas was reported to be $8.7 \%$. The PCR method was not used in the study. The prevalence of Toxoplasma in rats was reported to be 35\% in England. The results indicate that as is the case in cats, toxoplasmosis does not lead to particular symptoms in rats. The dominant type of toxoplasmosis in rats is the congenital type. It was demonstrated that in the wild life cycle of toxoplasmosis, rats play an important role as an intermediate host and reservoir (22). In another study, the prevalence of contamination of rats with Toxoplasma was reported to be $55.5 \%$ in the Philippines (23). In a study conducted in Iran on the strains of Toxoplasma, Zia Ali studied the prevalence of Toxoplasma strains in human and animal hosts (except for wild rats). It was demonstrated that $70 \%$ of the parasite isolates from humans and all of the isolates from the birds were type 3 of the parasite, and none of the isolates were type $1(24,25)$. So far, no appropriate or even serological study of the parasite has been carried out on rodents in the Iran

\section{Objectives}

Many wild rats live in Tehran; moreover these may play an important role as reservoirs and intermediate hosts of the parasite. Therefore, considering these points and also the state of Toxoplasma infections in Iran, the current study was carried out.

\section{Materials and Methods}

For this study, 40 wild rats were collected from the north, south, east, and west of Tehran using traps. The rats were anesthetized with ether and then killed. Their brains were extracted under sterile conditions, and were put into a container full of sterile physiological serum. The DNA of the samples was extracted using a phenol and chloroform method (26). We used a 529-bp repetitive sequence in the T. gondii genome (accession number 146527). The segment does not encode any protein, and repeats in the Toxoplasma genome 200-300 times. Thus, it has good sensitivity and specificity for the identification of the parasite. The sequences of the primers were as follows (27): SDKF (5-TTAGGTCTACGTGACACAGACGTC-3 SDKR (5 -CTGCAGACACAGTGCATCTGGATT-3`) PCR step for a total of 30 cycles, each consisting of $95^{\circ} \mathrm{C}$ for $45 \mathrm{~s}$, $55^{\circ} \mathrm{C}$ for $30 \mathrm{~s}$ and $72^{\circ} \mathrm{C}$ for $45 \mathrm{~s}$ were performed. An initial incubation at $95^{\circ} \mathrm{C}$ for three minutes, a final extension at $72^{\circ} \mathrm{C}$ for 10 minutes and final soak at $4^{\circ} \mathrm{C}$ was included. PCR products were directly sequenced by GenFanAvaran Co. The resulting sequences were completed and aligned using the programs; ChromasPro Version 1.32 (Technelysium Pty. Ltd., Qld, Australia) and ClustalW (http://www. ebi.ac.uk/Tools/msa/clustalw2/) and compared with reference sequences from GenBank.

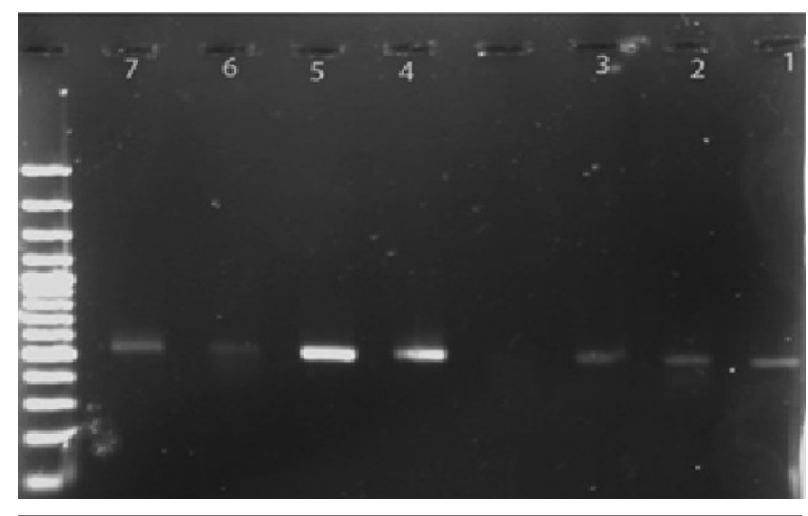

Figure 1. PCR Results on Agarose Gel. 


\section{Results}

Out of the 40 samples, 20 samples (50\%) were positive for the 529-bp band (specific for Toxoplasma) (Figure 1). Furthermore, in Table 1, the characteristics of the positive and negative samples are provided. The sequences of the isolates from the present study are accessible under GenBank accession nos. HM569597-603. By carrying out a PCR process on all samples, it was demonstrated that the brains of $50 \%$ of wild rats in Tehran are contaminated with Toxoplasma. The sequences of the seven samples were aligned with the data available in the GenBank, using available software. The results were obtained for each sample. Then, the nucleotide sequences of the seven samples were compared with each other, and the results were obtained. The nucleotides marked with a star were those that were identical in all samples. According to the alignment results obtained for the seven sequenced samples, the highest similarity was observed with the RH strain (81-95\%). of T. gondii, Toxoplasma was detected in 31 (50\%) wild rat brain samples using the PCR method. With regard to the sequences, the highest similarity was observed with the RH strain, and the alignment results of the seven samples can be classified as follows: 1- Similarity with the RH strain was 95\% and 92\% for samples No. 21 (Mehrabad airport) and No. 18 (Darakeh), respectively. As can be observed, their sequences had the highest similarity with the sequence of the RH strain.

It should be mentioned that the two samples were taken from two areas that are some distance from each other. 2- Samples No. 30 (Zafar) and 26 (Tehran Pars) had 87\% similarity with the RH strain. The similarity rate was $86 \%$ for sample No. 23 (Javanmard-e Ghasab). These three samples were also geographically distant, but had almost the same rate of sequence similarity.3-Similarity with the $\mathrm{RH}$ strain was $82 \%$ and $81 \%$ in samples No. 16 (Evin) and No.

\begin{tabular}{llllll}
\hline Table 1. Results of Toxoplasma Infection in the Brains of Wild Rats by PCR. & & & \\
\hline No. & Result of PCR & Region Name & No. & Result of PCR & Region Name \\
\hline 1 & negative & Hashemi & 21 & positive & Mehrabad \\
\hline 2 & positive & Rahahan & 22 & negative & Alghadir \\
3 & positive & Shohada & 23 & positive & Javanmard \\
\hline 4 & positive & Khalij & 24 & positive & Javanmard \\
\hline 5 & negative & Tehranpars & 25 & positive & Sadeghieh \\
\hline 6 & positive & Resalat & 26 & positive & Tehranpars \\
\hline 7 & positive & Sadeghieh & 27 & positive & Shohada \\
\hline 8 & positive & Emamhosein & 28 & positive & Sadeghieh \\
\hline 9 & negative & Zafar & 29 & positive & Alghadir \\
\hline 10 & positive & Hashemi & 30 & positive & Zafar \\
11 & positive & Polechobi & 31 & negative & Sadeque \\
\hline 12 & positive & Evin & 32 & negative & Satarkhan \\
13 & negative & Darband & 33 & negative & Rahahan \\
\hline 14 & negative & Evin & 34 & negative & Emamhosein \\
\hline 15 & negative & Tehranpars & 35 & negative & Khalij \\
\hline 16 & positive & Evin & 36 & negative & Shohada \\
\hline 17 & negative & Evin & 37 & negative & Hashemi \\
\hline 19 & positive & Darakeh & 38 & negative & Polechobi \\
\hline 5 & negative & Javanmard & 39 & negative & Satarkhan \\
\hline
\end{tabular}

\section{Discussion}

Toxoplasma gondii is a unicellular parasite, and it infects all types of warm-blooded vertebrates, including almost one third of the human population. Since the discovery of the parasite, numerous studies have been carried out to identify its; biological characteristics, antigenic components, epidemiological aspects, identification of the isoenzyme and molecular pattern, as well as other aspects. The result of these invaluable attempts is that extensive information is currently available on the organism. However, research on these aspects as well as the Lesser known aspects of the organism is still in progress. In our study on the role of wild rats as a potential source
28 (Sadeghieh). These two samples were also taken from geographically distant areas, but had almost the same rate of similarity. Most studies in Iran have been carried out on the epidemiological and diagnostic aspects of the parasite. We attempted to identify the contamination rate of wild rats in Tehran through genetic methods.

In previous studies in Iran, the prevalence of the parasite in their hosts has been determined using serological tests, and the highest prevalence was reported for pet birds (51\%). The study carried out by Zia Ali addressed the frequency of contamination in some hosts such as sheep and goats by the parasite, and the contamination rates were reported to be $22.8 \%$ and $14.3 \%$ for sheep and 
goats, respectively (25). In another study, Hashemi et al. determined the contamination rate of sheep and goats in the Qazvin, Kerman, and Azerbaijan provinces using the Latex method, and the rate was reported to be $24.3 \%$ and $20 \%$ for sheep and goats, respectively (28). In the studies carried out by Rahbari et al., using a direct agglutination test, the frequency of toxoplasmosis in sheep in the three areas of the Mazandaran province were determined to be $64.3 \%$, $54.5 \%$, and $49 \%$. It seems that the test method was effective as evidenced by the high rate of contamination (29).

Hoghughi et al. reported the frequency of toxoplasmosis in sheep and goats in the Khuzestan province to be $13.8 \%$ and $13.1 \%$, respectively (30). In the study carried out by Ghorbani et al. on pet birds using the IHA method, the prevalence of toxoplasmosis was reported to be $20.5 \%$ and 30.3\% in Tehran and Mazandaran, respectively (31). So far, no study has been carried out on toxoplasmosis in the brains of Iranian wild rats. Thus, we have selected wild rats for this study avoiding previously studied hosts. In most Iranian studies, serological methods have been employed, which are not as sensitive as molecular methods. Therefore, we used the PCR method in the current study.

In other countries, many studies have been carried out on the prevalence of toxoplasma in various hosts. The contamination rate was reported to be $0.8 \%$ in a study carried out in Grenada, West Indies, on 308 rats. In another study in England, the prevalence rate of Toxoplasma contamination in rats was determined to be $35 \%$, while in a similar study in the Philippines, the rate was reported to be $55.5 \%(22,32,33)$. According to our results, the contamination rate of Toxoplasma in the brains of wild rats in Tehran was determined to be $50 \%$ using the PCR method. In another study carried out on cats in Tehran, the rate was determined to be $89 \%$ (19). The rate obtained can be explained by the close relationship between cats and rats. Serological evaluation of rats for contamination by the parasite in a parallel study showed that $36.7 \%$ of rats in Tehran are contaminated with Toxoplasma (21). Considering the level of contamination of the cats by the parasite in Tehran and also the molecular and serological contamination rate of $50 \%$ and $36.7 \%$, respectively, it can be stated that rats play an important role in the preservation of the Toxoplasma life cycle in Tehran. Considering the sequence of the isolates, the highest similarity was observed for the $\mathrm{RH}$ strain, which ranged from $81 \%$ to $95 \%$.

This study is of environmental and sanitary interest. It is important for public health because of the close relationship between cats and rats. Based on the relatively high occurrence of this parasite in rats in Tehran, we have to consider these animals to be a major risk factor for the transmission of $T$. gondii in this area.

\section{Acknowledgements}

Herein, the kind cooperation of the research chancellor of the university and personnel of Department of Parasi- tology are highly appreciated.

\section{Financial Disclosure}

None declared.

\section{Funding Support}

Funding for this work was supported by the Research Chancellor of Tarbiat Modares University as the M.Sc. project.

\section{References}

1. Araujo F, Slifer T, Kim S. Chronic infection with Toxoplasma gondii does not prevent acute disease or colonization of the brain with tissue cysts following reinfection with different strains of the parasite. J Parasitol.1997;83 (3):521-2.

2. Charif H, Darcy F, Torpier G, Cesbron-Delauw MF, Capron A. Toxoplasma gondii: characterization and localization of antigens secreted from tachyzoites. Exp Parasitol.1990;71 (1):114-24.

3. Roberts TC, Storch GA. Multiplex PCR for diagnosis of AIDS-related central nervous system lymphoma and toxoplasmosis. J Clin Microbiol.1997;35(1):268-9.

4. Dubey JP. Advances in the life cycle of Toxoplasma gondii. Int Parasitol. 1998;28 (7):1019-24.

5. Schmidt GD, Roberts LS, Janovy J. Foundations of Parasitology. 5th ed. London: McGraw-Hill Education; 1995.

6. Roberts CW, Alexander J. Studies on a murine model of congenital toxoplasmosis: vertical disease transmission only occurs in $\mathrm{BALB} / \mathrm{C}$ mice infected for the first time during pregnancy. Parasitology. 1992;104 Pt 1:19-23.

7. Dubey JP, Lindsay DS, Speer CA. Structures of Toxoplasma gondii tachyzoites, bradyzoites, and sporozoites and biology and development of tissue cysts. Clin Microbiol Rev.1998;11 (2):267-99.

8. Denkers EY, Gazzinelli RT. Regulation and function of T-cellmediated immunity during Toxoplasma gondii infection. Clin Microbiol Rev. 1998;11 (4):569-88.

9. Zoghei. [Toxoplasmosis in Humans and Animals].Tehran Islamic Culture Publishing Office. 1983;1.

10. Fuentes I, Rodriguez M, Domingo CJ, del Castillo F, Juncosa T, Alvar J. Urine sample used for congenital toxoplasmosis diagnosis by PCR. J Clin Microbiol. 1996;34 (10):2368-71.

11. Pinon JM, Foudrinier F, Mougeot G, Marx C, Aubert D, Toupance $\mathrm{O}$, et al. Evaluation of risk and diagnostic value of quantitative assays for anti-Toxoplasma gondii immunoglobulin A (IgA), IgE, and IgM and analytical study of specific IgG in immunodeficient patients. J Clin Microbiol. 1995;33 (4):878-84.

12. Degerli K, Kilimcioglu AA, Kurt O, Tamay AT, Ozbilgin A. Efficacy of azithromycin in a murine toxoplasmosis model, employing a Toxoplasma gondii strain from Turkey. Acta Trop. 2003;88 (1):45-50.

13. Soleh Joe K. Evaluation test set for diagnosis of toxoplasmosis ELISA pot [Thesis]. Tehran: Tarbiat Modarres University; 1990.

14. Hejazi H. Survey and isolation of Toxoplasma gondii strains in the Isfahan [Thesis]. Tehran: Tarbiat Modarres University; 1979.

15. Mardanei A. Toxoplasma gondii sero-epidemiological infection in pregnant women in the Qoem by ELISA and IFA methods [Thesis]. Tehran: Tehran Medical Sciences University; 1993.

16. Rahnema B. Prevalence of toxoplasmosis in pregnant women and non pregnant in the Tabriz [Thesis]. Tehran: Tehran Medical Sciences University. 1992.

17. Rastaqy A. Prevalence of Toxoplasma infection in pregnant women and their infant's in Amol city. Fourth Conference on Parasitology and parasitic disease; 1993; Iran, Mashhad University of Medical Sciences. 1993.

18. Shoaei H. Toxoplasma gondii sero-epidemiological infection in pregnant women referred to Imam Hossein Hospital, Zanjan by ELISA method [Thesis]. Tehran: Tehran Medical Sciences University; 1993. 
19. Tabaei J. Survey of toxoplasmosis in stray cats in Tehran [Thesis]. Tehran: Tarbiat Modarres University; 1981.

20. Hamidinejat H, Mosalanejad B, Avizeh R, Jalali MHR, Ghorbanpour M, Namavari M. Neospora caninum and Toxoplasma gondii antibody prevalence in Ahvaz feral cats, Iran. Jundishapur J Microbiol. 2012;4 (4):217-22.

21. Mahmodzadeh A, Sadraei J, Mokhtari Khojaste R. Survey of Toxoplasma Gondii Iinfection Rate in Rattus by Elisa Method in Tehran. Modares J Med Sci (Pathobiol). 2011.

22. Webster JP. Prevalence and transmission of Toxoplasma gondii in wild brown rats, Rattus norvegicus. Parasitology. 1994;108 ( Pt 4):407-11.

23. Cabanacan C. Toxoplasma gondii infection in philippines rattus sp confirmed through bioassay in mus musculus.J Parasitol 2006:544-600.

24. Ajzenberg D, Banuls AL, Su C, Dumetre A, Demar M, Carme B, et al. Genetic diversity, clonality and sexuality in Toxoplasma gondii. Int J Parasitol. 2004;34 (10):1185-96.

25. Zia-Ali N, Fazaeli A, Khoramizadeh M, Ajzenberg D, Darde M, Keshavarz-Valian H. Isolation and molecular characterization of Toxoplasma gondii strains from different hosts in Iran. Parasitol Res. 2007;101 (1):111-5.

26. Sambrook J, Fritsch EF, Maniatis T. Molecular Cloning: A Laboratory
Manual. 2nd ed. Cold Spring Harbor: Cold Spring Harbor Laboratory Press; 1989.

27. Kazemi B. Early diagnosis of congenital toxoplasmosis in rats using blood by PCR method [Thesis]. Tehran: Tarbiat Modarres University 1992.

28. Hashemi-Fesharki R. Seroprevalence of Toxoplasma gondii in cattle, sheep and goats in Iran. Vet Parasitol. 1996;61 (1-2):1-3.

29. Rahbari S, Razmi GR. Seroepidemiologial study of Toxoplasmosis in sheep in Mazandaran provience, Iran. J Mazandaran Univ Med Sci.1998;50:39-49.

30. Navidpour S, Hoghooghi-rad N. Seroprevalence of anti-Toxoplasma gondii antibodies in buffaloes in Khoozestan province, Iran Vet Parasitol. 1998;77 (2-3):191-4.

31. Ghorbani M, Edrissian GH, Assad N. Serological survey of toxoplasmosis in the northern part of Iran, using indirect fluorescent antibody technique. Trans R Soc Trop Med Hyg. 1978;72 (4):369-71.

32. Dubey JP, Bhaiyat MI, Macpherson CN, de Allie C, Chikweto A, Kwok OC, et al. Prevalence of Toxoplasma gondii in rats (Rattus norvegicus) in Grenada, West Indies.J Parasitol. 2006;92 (5):1107-8.

33. Zimmer C, Daeschlein G, Patt S, Weigel K. Strategy for diagnosis of Toxoplasma gondii in stereotactic brain biopsies. Stereotact Funct Neurosurg. 1991;56 (1):66-75. 